\title{
Understanding and Exploitation of Neighboring Heteroatom Effect for the Mild N- arylation of Heterocycles with Diaryliodonium Salts under Aqueous Conditions: A Theoretical and Experimental Mechanistic Study
}

\author{
Tamás Bihari ${ }^{1}$, Bence Babinszki ${ }^{1}$, Zsombor Gonda ${ }^{2}$, Szabolcs Kovács ${ }^{2}$, Zoltan Novák ${ }^{2 *}$, András \\ Stirling ${ }^{*}$ \\ ${ }^{1}$ Institute of Organic Chemistry, Research Centre for Natural Sciences of the Hungarian Academy of Sciences, \\ Magyar Tudósok Körútja 2, H-1117 Budapest, Hungary \\ ${ }^{2}$ MTA-ELTE "Lendület" Catalysis and Organic Synthesis Research Group, Institute of Chemistry, Eötvös \\ University, Pázmány Péter sétány 1/a H-1117 Budapest, Hungary
}

\begin{abstract}
The mechanism of arylation of $N$-heterocycles with unsymmetric diaryliodonium salts is elucidated. The fast and efficient $\mathrm{N}$-arylation reaction is interpreted in terms of the bifunctionality of the substrate: the consecutive actions of properly oriented Lewis base and Brønsted acid centers in sufficient proximity result in the fast and efficient $N$-arylation. The mechanistic picture points to a promising synthetic strategy where suitably positioned nucleophilic and acidic centers enables functionalization and it is tested experimentally.
\end{abstract}

\section{INTRODUCTION}

In the past two decades hypervalent, $\lambda^{3}$-iodane organic compounds have been efficiently utilized as successful reagents in organic chemistry. ${ }^{1-2}$ This rising interest in $\lambda^{3}$-iodanes is mainly due to their versatile character, commercial availability, environmental-friendly behavior and enormous potential in $\mathrm{C}-\mathrm{C}$ and $\mathrm{C}$-heteroatom couplings. Diaryliodonium salts are particularly important among the quickly growing number of aryliodonium compounds because they afford efficient arylation of diverse nucleophiles, in particular heteroatom nucleophiles. ${ }^{2}$ While arylation with iodonium salts often requires the presence of transition-metal catalysts, ${ }^{3}$ recently efficient 
metal-free alternative arylation procedures have been developed, ${ }^{4-7}$ which offer various advantages, such as less toxicity, higher moisture and air tolerance and lower costs. These transformations generally require strong bases.

Earlier studies have already pointed out several important aspects of the mechanism of metalfree arylation by iodonium salts. While in some cases radical mechanism was observed, ${ }^{8}$ a large number of arylation reactions follow nonradical pathways. ${ }^{7,9-16}$ It has been showed both theoretically $^{10,11,17-20}$ and experimentally ${ }^{7,11,12,21}$ that the chemoselectivity of the unsymmetrical aryliodonium salts are governed by the interplay of the electron deficiencies of the aromatic rings attached to the iodine center and the steric demand of the ortho ligands on the aryl groups (orthoeffect ${ }^{22}$ ). Quantum chemical calculations have also shown that the selectivity can be predicted by considering the differences between the activation barriers of the sigmatropic rearrangements. $^{10,11,18,19}$

Recently calculations have indicated that the [2,3]-sigmatropic rearrangement is a more favorable pathway for $\alpha$-arylation of enolates than the expected [1,2]-rearrangement route, ${ }^{10}$ and subsequent experimental work on $\mathrm{N}$-arylation of secondary amides also suggested this route. ${ }^{14}$

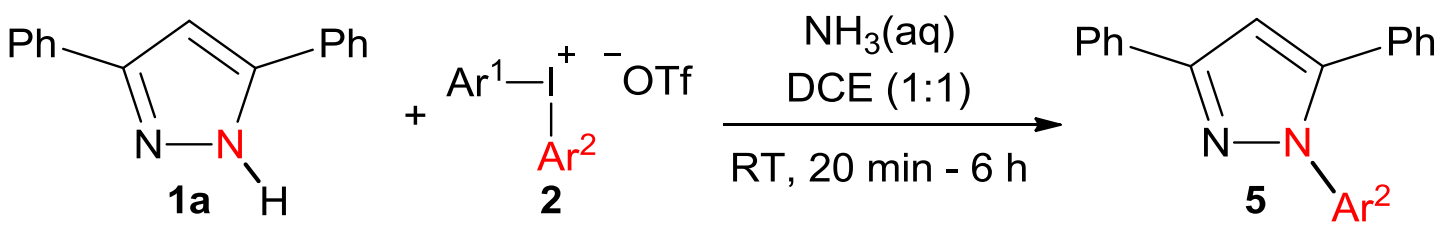

Scheme 1. $N$-arylation of 3,5-diphenylpyrazole with unsymmetric diaryliodonium triflate. ${ }^{9}$

Direct arylation of nitrogen-heterocycles is an advantageous way to obtain functionalized heterocycles at a lower cost. Aryliodonium salts have also been proved to be very efficient for both $\mathrm{C}-\mathrm{H}$ arylation and $N$-functionalization. ${ }^{1 \mathrm{c}, 2 \mathrm{a}, 2 \mathrm{c}}$ For example $N$-arylated pyrazoles have been recently synthetized using diaryliodonium salts (Scheme 1). ${ }^{9} \mathrm{~N}$-arylated pyrazoles are frequently 
used molecular motifs for biologically active compounds in medicinal chemistry, therefore functionalization of pyrazole scaffolds is highly beneficial. A particular advantage of the methodology is that weak bases are sufficient for optimal performance. The efficiency and the wide scope of this method offers an ideal opportunity to study the mechanistic aspects of the direct arylation reactions with iodonium salts. To this end we have followed a computational strategy where we first probed different possible reaction paths and selected the optimal mechanism by comparing the free energy profiles. The insights obtained from the results lead us to postulate a more general mechanistic pattern for the arylation reactions. Then we have tested this mechanism by predicting the chemoselectivity of the arylation reactions of a diverse set of unsymmetric iodonium salts taken from our previous work. ${ }^{9}$ On the basis of the generalized mechanism we can identify additional scaffolds suitable for $\mathrm{N}$-arylation under mild conditions which further extend the scope of the methodology.

\section{RESULTS AND DISCUSSION}

We have applied density functional theory and the same methodological framework as in our earlier study to explore the mechanism of trifluoroethylation of indoles. ${ }^{23}$ For identifying the initial resting state we first focused on the possible solvated forms of the iodonium salt. Three conformations (depending on the equatorial ligand) and the dissociated form have been considered. We have found that the most stable state is the dissociated form by a few $\mathrm{kcal} / \mathrm{mol}$ for several iodonium salts. ${ }^{24}$ Earlier calculations predicted that the dissociated state is less stable by $1.7 \mathrm{kcal} / \mathrm{mol}$ when the solvent is THF. ${ }^{10}$ This discrepancy points to a role of the solvent in the mechanism. 


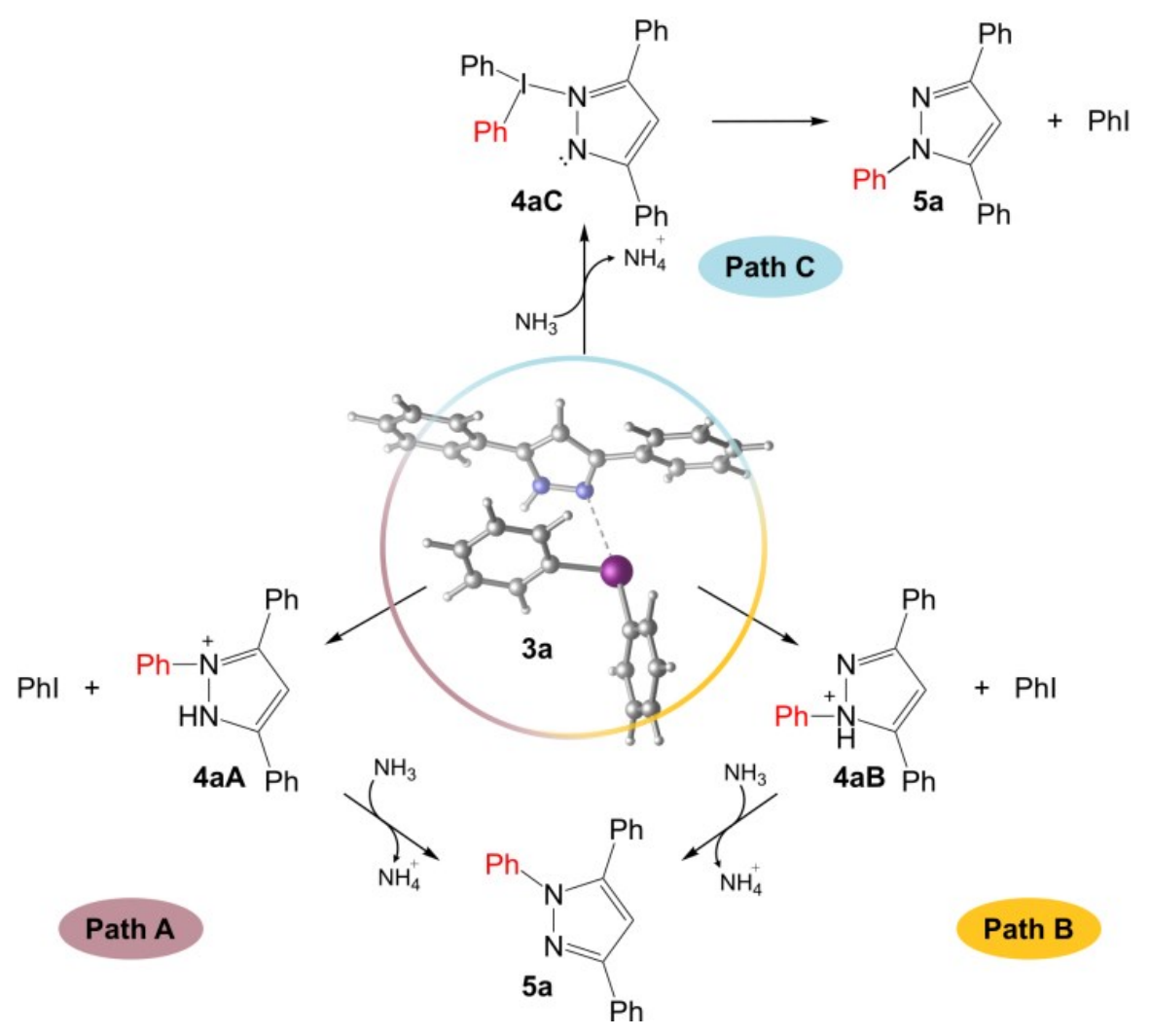

Figure 1. Possible reaction mechanisms for the arylation with diaryliodonium cation.

We have chosen the reaction between 3,5-diphenylpyrazole (1a) and diphenyliodonium triflate (2a) as our model system. Three possible pathways can be devised for the arylation reaction which are displayed in Figure 1. All the three pathways start with the formation of the T-shape adduct from the substrate and the iodonium cation in line with earlier predictions. ${ }^{10,11,17,19}$ At variance with other substrates here the iodonium cation forms a bond with the neighbor $N$ atom which is in fact an efficient Lewis base. ${ }^{25}$ Along route A the arylation proceeds via a [1,2]rearrangement which is followed by the deprotonation of the neighbor $N$ atom by $\mathrm{NH}_{3}$. According to mechanism B the adduct is formed with the $N$ atom of the acidic NH moiety and then it undergoes a [2,2]-rearrangement. The proton is subsequently transferred to $\mathrm{NH}_{3}$. Along route $\mathrm{C}$ the adduct first undergoes a deprotonation by the base $\mathrm{NH}_{3}$ followed by the [2,2]-rearrangement and the release of phenyl-iodide. 


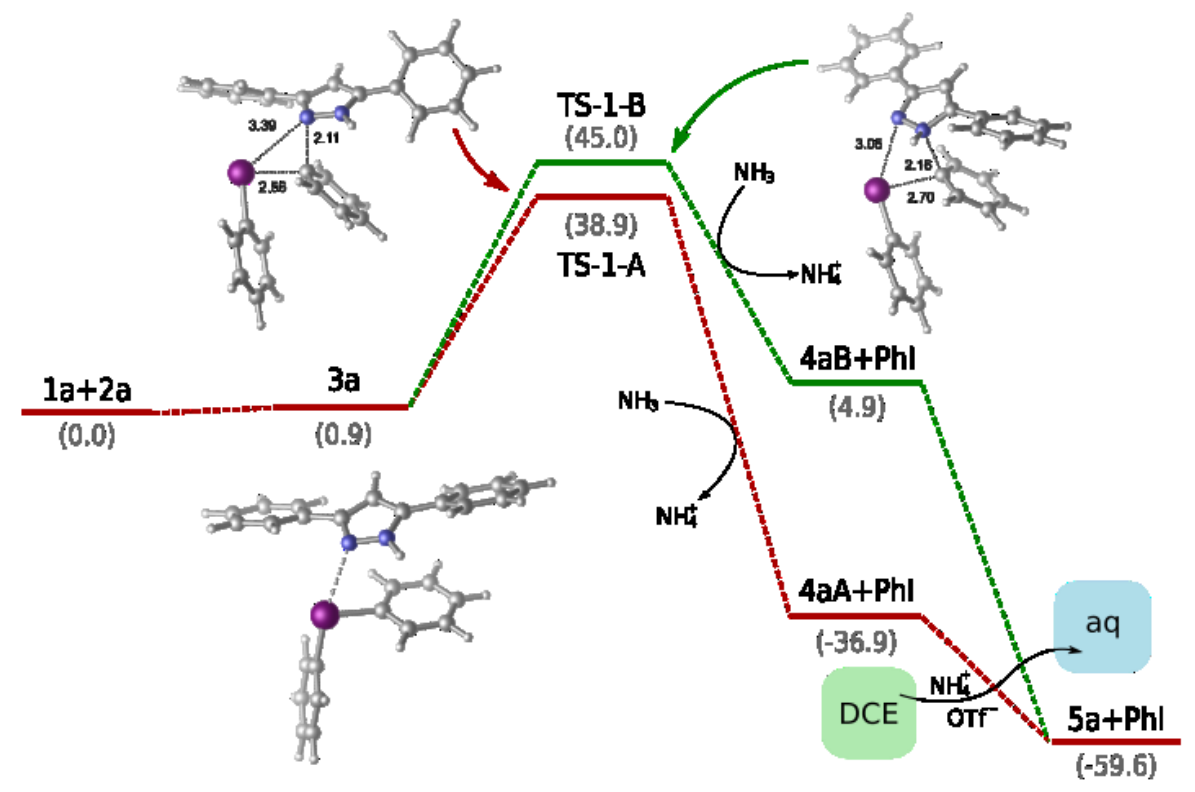

Figure 2. Free energy profiles for paths A and B. Red: path A; green: path B. Values are in $\mathrm{kcal} / \mathrm{mol}$.

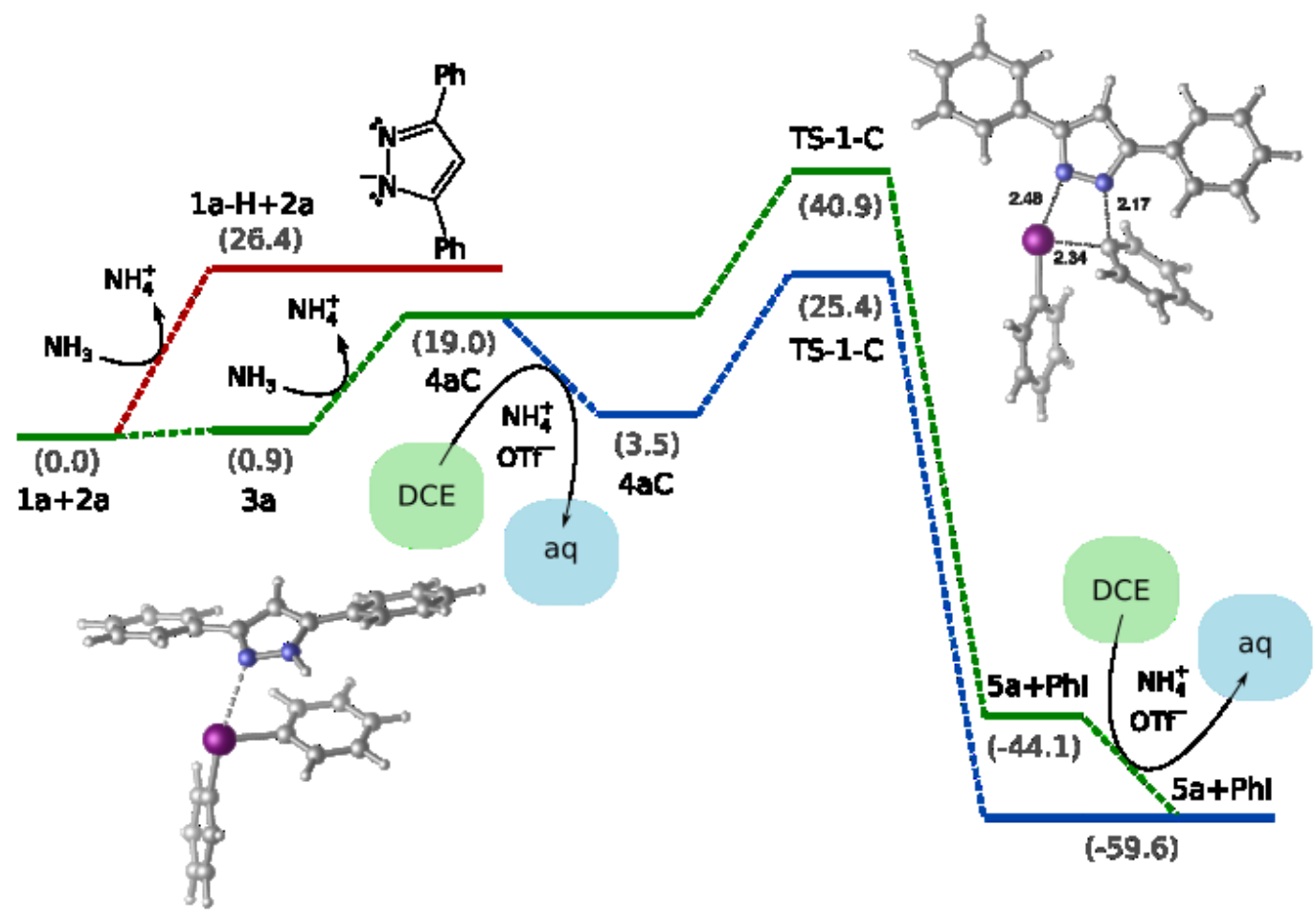

Figure 3. Free energy profiles for path C. Values are in $\mathrm{kcal} / \mathrm{mol}$. 
Figure 2 shows the calculated free energy profiles for routes A and B. On both paths the first step is the formation of adduct 3a from the pyrazole substrate and the iodonium cation. Then the $N$-arylation by [1,2]-rearrangement goes through a $38.9 \mathrm{kcal} / \mathrm{mol}$ free energy barrier, whereas the [2,2]-rearrangement on path $\mathrm{B}$ has a somewhat higher, $45.0 \mathrm{kcal} / \mathrm{mol}$ barrier. In the last step the intermediates are deprotonated by $\mathrm{NH}_{3}$ yielding product 5a. The profiles show a significantly exergonic reaction. On the other hand the barriers are not compatible with the mild experimental conditions and suggest that the reaction follows another mechanism. Note that both paths A and B indicate that the deprotonation of the cationic intermediates is a very favorable process. In fact this is the key for the favorable pathway. Figure 3 shows three variants of path $\mathrm{C}$ where the deprotonation preceeds the $N$-arylation step. Deprotonation of the reactant pyrazole molecule is not favorable $(+26.4 \mathrm{kcal} / \mathrm{mol}$ endergonicity). On the other hand, deprotonation of intermediate 3a needs a considerably smaller, $19.0 \mathrm{kcal} / \mathrm{mol}$ free energy investment which implies that the adduct formation increases remarkably the acidity of the neighbor N-H moiety. ${ }^{25}$ This can be due to the extra positive charge carried by the iodonium cation which induces a limited destabilization to the neighbor $\mathrm{N}-\mathrm{H}$ moiety. A subsequent $\mathrm{N}$-arylation would require an additional $21.9 \mathrm{kcal} / \mathrm{mol}$ free energy investment to go through the activation barrier of $40.9 \mathrm{kcal} / \mathrm{mol}$. After passing the barrier the reaction is accompanied by a large free energy release due to the formation of iodobenzene and the $N$-aryl bond. The final part of the reaction energy is recovered when the byproducts $\mathrm{NH}_{4}{ }^{+}$and triflate counteranion are transferred from the organic phase to the aqueous phase.

A crucial observation is that aqueous solvation of the ionic byproducts can occur earlier along the paths and in fact this can remarkably improve the barrier along route $\mathrm{C}$. Indeed, transfer of the ion pair to the aqueous phase is an exergonic process with $-15.5 \mathrm{kcal} / \mathrm{mol}$ free energy. As Figure 3 
shows, when this process is taken into account at the deprotonation stage, the barrier of the $\mathrm{N}$ arylation is only $25.4 \mathrm{kcal} / \mathrm{mol}$ which explains the experimental observations.

On the basis of profile $\mathrm{C}$ we can formulate the following mechanistic picture. The reaction starts with the association of the iodonium cation with a neighbor nucleophilic, ie. Lewis base site forming a T-shape adduct. The arylation takes place on the heteroatom carrying the acidic proton. The transfer of one of the aryl ligands is the rate detemining step. It is preceded by the deprotonation of the complex. The main motif of this mechanism is the consecutive actions of the neighbor Lewis base and Brønsted acid centers of the substrate: they enable a more favorable 4membered cyclic TS, as opposed to a 3-membered TS in the less favorable pathway. At variance with other methods employing strong bases here the presence of aqueous phase assists to stabilize the intermediate undergoing the intramolecular arylation.

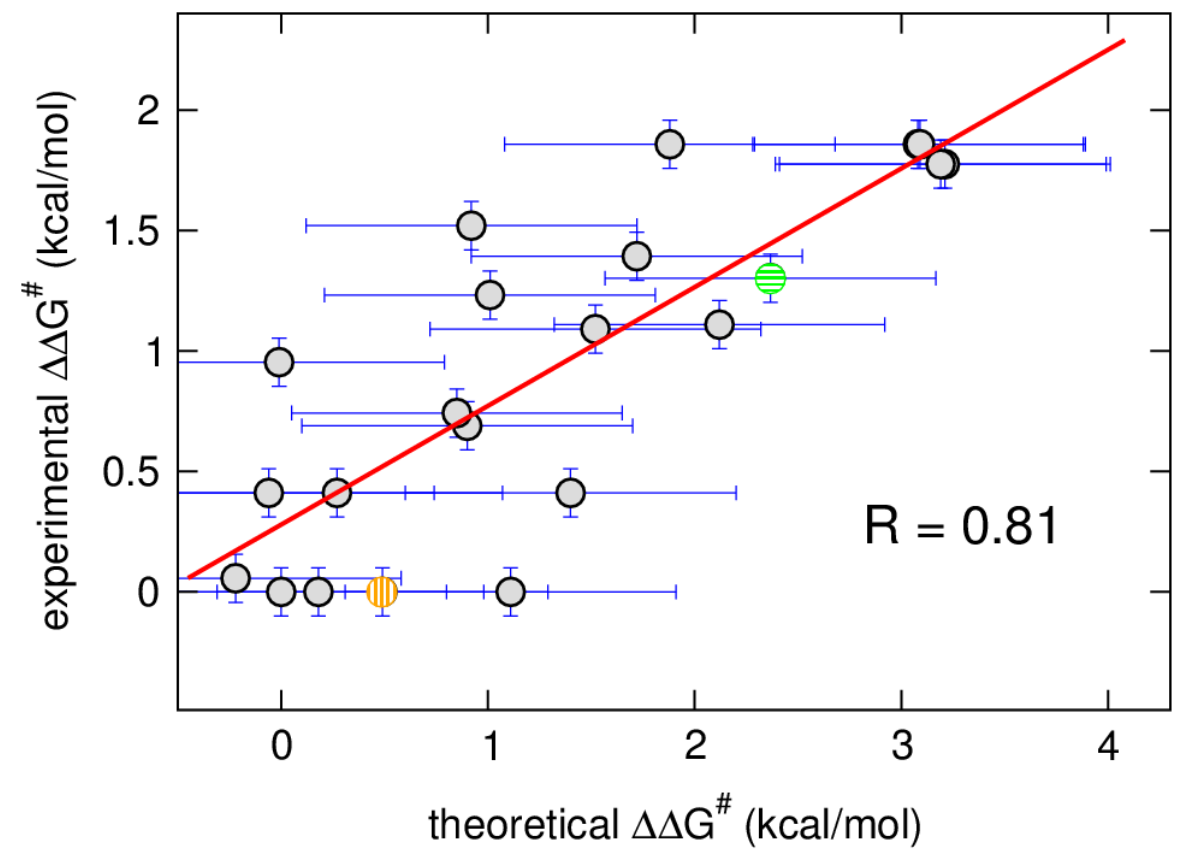

Figure 4. Theoretical versus experimental $\Delta \Delta \mathrm{G}^{\#}$ of the $N$-arylation of 3,5-diphenylpyrazole with unsymmetric iodonium salts. $\Delta \Delta \mathrm{G}^{\#}$ is the difference between the activation free energies of the two possible arylations. ${ }^{27}$ Only those reactions are included where both products have been observed. The linear regression line is red. The experimental error bar $( \pm 0.1 \mathrm{kcal} / \mathrm{mol})$ is derived from an estimated $5 \%$ concentration gross uncertainty of the experimental determination of the final concentration ratios. The theoretical error bar has been set to $\pm 0.8 \mathrm{kcal} / \mathrm{mol}$ 
which is a typical uncertainty for solvent models. ${ }^{28}$ A more elaborated error analysis is given in the SI. Colored data points are explained in the text.

The high exergonicity and the moderate barrier indicate that the selectivity of the arylation is kinetic in origin. To test this hypothesis, we have considered a large body of experimentally observed arylation reactions of 3,5-diphenylpyrazole with unsymmetric diaryliodonium salts and calculated their free energy barriers. ${ }^{26}$ Comparison of the theoretical predictions with experimental observations in terms of activation free energy differences is plotted out on Figure 4. The plot is somewhat scattered, mainly due to the potential errors in the calculated values. ${ }^{30}$ To illustrate the concept of this plot we highlighted two data-points. The orange (horizontal hatched) data point represents the selectivity between $p$-Br-phenyl and phenyl groups where the experimental product ratio is $1: 1$, although the theory predicted a small, $0.49 \mathrm{kcal} / \mathrm{mol}$ activation energy difference favoring arylation by the $p$ - $\mathrm{Br}-\mathrm{Ph}$ group. In contrast, the green (vertical hatched) data point shows that both experiment and theory predict in nice accord high selectivity for $o$-Br-phenyl group with respect to phenyl group (experimental product ratio is 9:1 which is equivalent to $1.30 \mathrm{kcal} / \mathrm{mol}$ barrier difference while the theory predicts $2.37 \mathrm{kcal} / \mathrm{mol}$ ). Overall we see that our methodology has a general tendency to slightly overestimate the experimental selectivities. This implies that we can confidently predict the high selectivity cases, whereas in the less selective cases the uncertainty is relatively larger. With that in mind we can conclude that the chemoselectivity observed here is indeed kinetically controlled, in line with earlier findings ${ }^{11}$ for other substrates. 


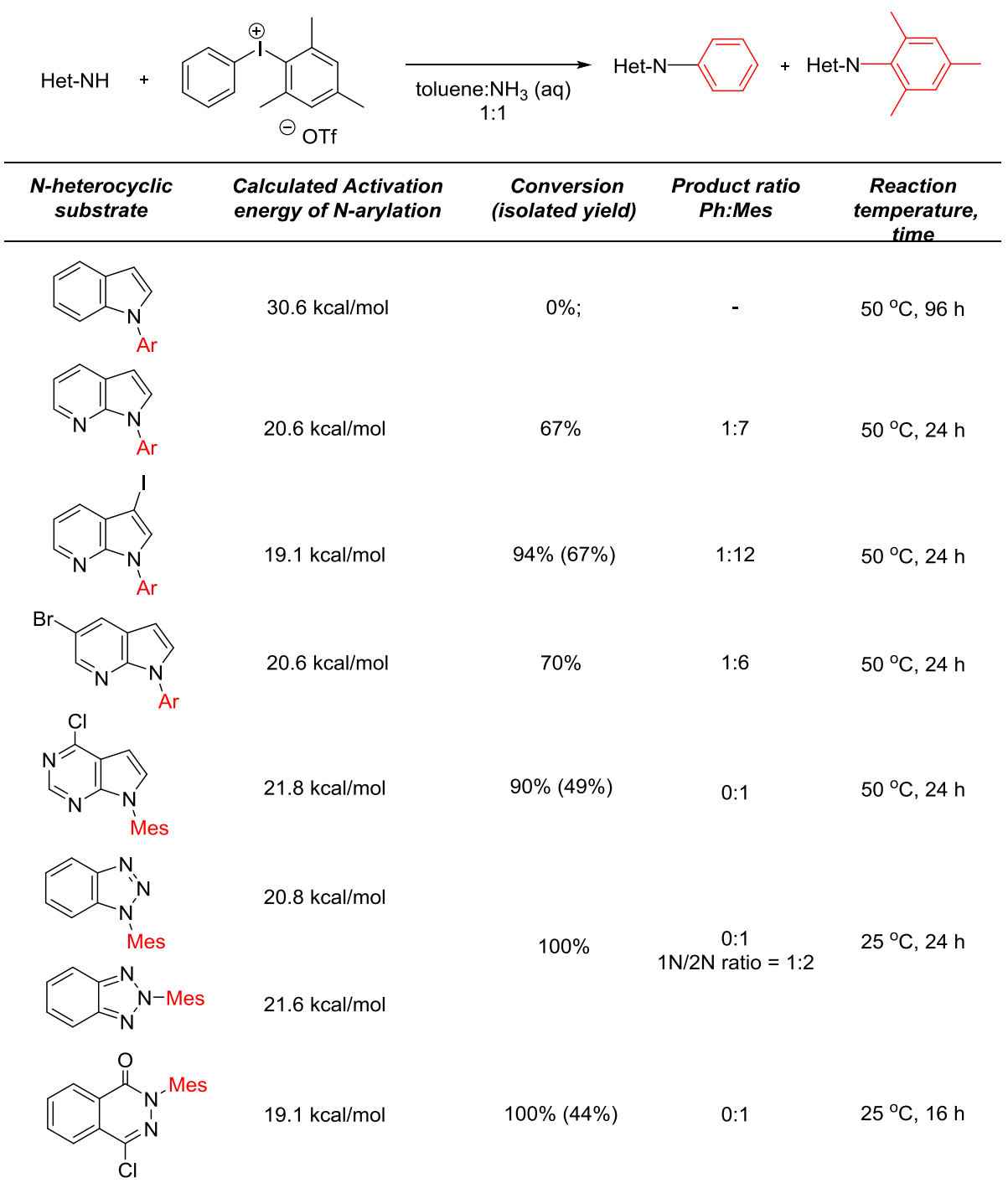

Figure 5. Arylation products obtained from the $N$-arylation of various heterocycles with phenyl(mesityl)iodonium triflate and the experimental conditions. The arylations of the present work have been performed in 1:1 toluene $25 \% \mathrm{NH}_{3}$ solution. The calculated activation barriers $(\mathrm{kcal} / \mathrm{mol})$, conversions, product ratio and isolated yields in parentheses are indicated.

The mechanistic pattern indicates that other substrates featuring a strategically positioned Lewis base (nucleophilic) and Brønsted acidic centers in close vicinity can also undergo facile arylation with diaryliodonium salts under mild conditions with the same mechanism. This prediction has been tested on a limited set of substrates (Figure 5) by calculations and also confirmed experimentally. Selection of these substrates was guided by the criterion to exclude the ambiguity brought by tautomerism between the two vicinal $\mathrm{N}$-sites of the original pyrazole 
frames. Figure 5 shows that the new substrates can be arylated in acceptable to good yield with the present methods. On the other hand indole, where this mechanism cannot work, is inactive in this reaction. ${ }^{29}$ In addition we invoked here three recent examples from the literature ${ }^{10,14,16}$ with $C, N$ and $O$-functionalization, where the present mechanism can be postulated, although the experimental conditions vary considerably (Fig. 6). These examples demonstrate that detailed insight into the mechanism efficiently helps in extending the scope of the method. However, we note that further optimization of the conditions for the new substrates is necessary for amplifying the potential of this synthetic strategy.
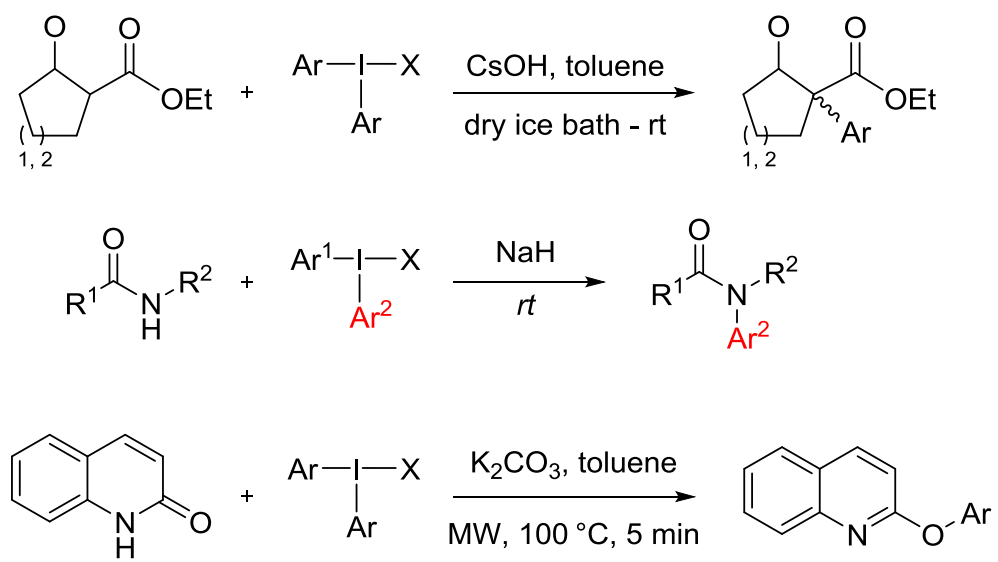

Figure 6. Recent literature examples where the present mechanism was postulated ${ }^{10,14}$ or it can be assumed via the iminol tautomer. ${ }^{16}$

\section{CONCLUSIONS}

In conclusion, we have successfully explored the reaction mechanism of the $N$-arylation of pyrazoles with diaryliodonium salts. We find that the close vicinity of the two $N$ atoms plays a crucial role in the mechanism: the nucleophilic (Lewis-base) $N$-site supports the iodonium ion while the $N$ atom of the Brønsted acid N-H moiety is arylated. This tandem action enables the 
employment of weak, aqueous base in the reaction facilitating the formation of the deprotonated iodonium substrate precursor for arylation. We have also shown that the mechanistic pattern is more general and on the basis of the mechanism other substrates could also be identified and functionalized by unsymmetric diaryliodonium salt under mild conditions.

\section{EXPERIMENTAL SECTION}

\section{General Informations}

Unless otherwise indicated, all starting materials were obtained from commercial suppliers, and were used without further purification. Analytical thin-layer chromatography (TLC) was performed on Merck DC pre coated TLC plates with $0.25 \mathrm{~mm}$ Kieselgel $60 \mathrm{~F}_{254}$. Visualization was performed with a $254 \mathrm{~nm}$ UV lamp. The ${ }^{1} \mathrm{H},{ }^{13} \mathrm{C}$ and ${ }^{19} \mathrm{~F}$ NMR spectra were recorded on a Bruker Avance-250 spectrometer and in $\mathrm{CDCl}_{3}, \mathrm{D}_{3} \mathrm{COD}, \mathrm{CD}_{3} \mathrm{CN}$ and DMSO- $d_{6}$. Chemical shifts are expressed in parts per million $(\delta)$ using residual solvent protons as internal standards $(\delta 7.26$

for ${ }^{1} \mathrm{H}, \delta 77.0$ for $\left.{ }^{13} \mathrm{C}\right)$. Coupling constants $(J)$ are reported in Hertz $(\mathrm{Hz})$. Splitting patterns are designated as $\mathrm{s}$ (singlet), $\mathrm{d}$ (doublet), $\mathrm{t}$ (triplet), $\mathrm{q}$ (quartet), $\mathrm{m}$ (multiplet). Combination gas chromatography and low resolution mass spectrometry was obtained on an Agilent 6890N Gas Chromatograph (30 m x $0.25 \mathrm{~mm}$ column with $0.25 \mu \mathrm{m}$ HP-5MS coating, He carrier gas) and Agilent 5973 Mass Spectrometer (Ion source: $\mathrm{EI}+, 70 \mathrm{eV}, 230^{\circ} \mathrm{C}$; interface: $300^{\circ} \mathrm{C}$ ). IR spectra were obtained on a Bruker IFS55 spectrometer on a single-reflection diamond ATR unit. All melting points were measured on Büchi 501 apparatus and are uncorrected. High-resolution mass spectra were acquired on an Agilent 6230 time-of-flight mass spectrometer equipped with a Jet Stream electrospray ion source in positive ion mode. Injections of $0.1-0.3 \mu 1$ were directed to the mass spectrometer at a flow rate $0.5 \mathrm{ml} / \mathrm{min}$ ( $70 \%$ acetonitrile-water mixture, $0.1 \%$ formic acid), 
using an Agilent 1260 Infinity HPLC system. Jet Stream parameters: drying gas $\left(\mathrm{N}_{2}\right)$ flow and temperature: $10.0 \mathrm{l} / \mathrm{min}$ and $325^{\circ} \mathrm{C}$, respectively; nebulizer gas $\left(\mathrm{N}_{2}\right)$ pressure: 10 psi; capillary voltage: $4000 \mathrm{~V}$; sheath gas flow and temperature: $325^{\circ} \mathrm{C}$ and $7.51 / \mathrm{min}$; TOFMS parameters: fragmentor voltage: $120 \mathrm{~V}$; skimmer potential: 120V; OCT 1 RF Vpp:750 V. Full-scan mass spectra were acquired over the $\mathrm{m} / \mathrm{z}$ range $100-2500$ at an acquisition rate of $250 \mathrm{~ms} / \mathrm{spectrum}$ and processed by Agilent MassHunter B.03.01 software.

\section{General procedure for the synthesis of $N$-arylated heterocycles}

The appropriate $N$-heterocycle $(0.5 \mathrm{mmol}, 1.0$ equiv $)$, diaryliodonium salt $(0.55 \mathrm{mmol}, 1.1$ equiv), were placed in a $30 \mathrm{ml}$ vial and dissolved in $25 \mathrm{w} / \mathrm{w} \% \mathrm{NH}_{3}$ (aq) solution-toluene 1:1 (20 $\mathrm{mL})$ stirred at RT for the indicated time. The reaction mixture was diluted with $\mathrm{CH}_{2} \mathrm{Cl}_{2}(10 \mathrm{~mL})$. The aqueous layer was extracted with $\mathrm{CH}_{2} \mathrm{Cl}_{2}(2 \times 10 \mathrm{~mL})$ and all combined organic phase were dried over magnesium sulphate. The suspension was then filtered, concentrated in vacuo and purified by flash chromatography on silicagel, if not noted otherwise.

Indole: the reaction did not take place even after 96 hours $(0 \%$ conversion $)$, the starting material was recovered in $89 \%(52 \mathrm{mg})$.

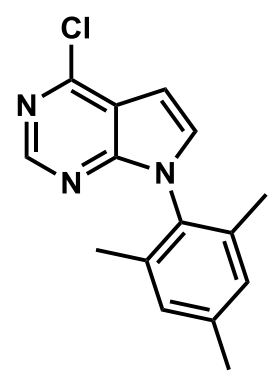

\section{4-Chloro-7-mesityl-7H-pyrrolo[2,3-d]pyrimidine}

The general procedure was followed $\left(24 \mathrm{~h}, 50^{\circ} \mathrm{C}\right)$. GC-MS conversion: $90 \%$, off-white solid (66 mg, 0.25 mmol, yield: 49\%). $\mathrm{R}_{\mathrm{f} .:} 0.49$ (in hexane:EtOAc 4:1), M.p.: $117-118{ }^{\circ} \mathrm{C},{ }^{1} \mathrm{H}$ NMR $(250$ 
$\left.\mathrm{MHz}, \mathrm{CDCl}_{3}\right) \delta 8.62(\mathrm{~s}, 1 \mathrm{H}), 7.23(\mathrm{~d}, J=3.6 \mathrm{~Hz}, 1 \mathrm{H}), 7.04(\mathrm{~s}, 2 \mathrm{H}), 6.81(\mathrm{~d}, J=3.6 \mathrm{~Hz}, 1 \mathrm{H}), 2.37$ $(\mathrm{s}, 3 \mathrm{H}), 1.90(\mathrm{~s}, 6 \mathrm{H}) \mathrm{ppm} .{ }^{13} \mathrm{C}$ NMR $\left(63 \mathrm{MHz}, \mathrm{CDCl}_{3}\right) \delta 152.77,151.8,151.6,139.9,136.4$, 132.4, 130.8, 129.7, 117.6, 100.8, 21.5, 18.0 ppm. MS (EI, $70 \mathrm{eV}): \mathrm{m} / z(\%): 271\left(38,\left[\mathrm{M}^{+}\right]\right), 236$ (5), 208 (100), 193 (16), 167 (6), 115 (16), 91 (19), 77 (17). IR (ATR), 1585, 1544, 1510, 1488, $1454,1413,1354,1279,1246,1208,1149,988,910,850,731 \mathrm{~cm}^{-1}$. HRMS calcd for $\mathrm{C}_{15} \mathrm{H}_{15} \mathrm{ClN}_{3}$ $[\mathrm{M}+\mathrm{H}]^{+} 272.0949$ found 272.0953<smiles>Cc1cc(C)c(-n2nc(Cl)c3ccccc3c2=O)c(C)c1</smiles>

\section{4-Chloro-2-mesitylphthalazin-1(2H)-one}

The general procedure was followed $\left(16 \mathrm{~h}, 25^{\circ} \mathrm{C}\right) \mathrm{GC}-\mathrm{MS}$ conversion: $100 \%$. off-white solid (65 mg, 0.22 mmol, yield: 44\%). $\mathrm{R}_{\mathrm{f}}: 0.37$ (in hexane:EtOAc 4:1), M.p.: $143-144{ }^{\circ} \mathrm{C},{ }^{1} \mathrm{H}$ NMR $(250$ $\left.\mathrm{MHz}, \mathrm{CDCl}_{3}\right) \delta 8.54(\mathrm{dd}, J=7.8,1.5 \mathrm{~Hz}, 1 \mathrm{H}), 8.09(\mathrm{dd}, J=7.5,1.5 \mathrm{~Hz}, 1 \mathrm{H}), 8.04-7.81(\mathrm{~m}$, 2H), $7.00(\mathrm{~s}, 2 \mathrm{H}), 2.34(\mathrm{~s}, 3 \mathrm{H}), 2.11(\mathrm{~s}, 6 \mathrm{H}) \mathrm{ppm} .{ }^{13} \mathrm{C} \mathrm{NMR}\left(63 \mathrm{MHz}, \mathrm{CDCl}_{3}\right) \delta$ 158.8, 139.4, 138.8, 137.0, 135.3, 134.4, 133.2, 129.7, 129.3, 128.4, 126.3, 21.5, 18.0 ppm. MS (EI, $70 \mathrm{eV}$ ):

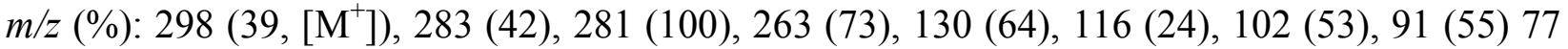
(24). IR (ATR), 1667, 1611, 1581, 1544, 1484, 1454, 1339, 1290, 1272, 1171, 996, 850, 772, 727, $690 \mathrm{~cm}^{-1}$. HRMS calcd for $\mathrm{C}_{17} \mathrm{H}_{15} \mathrm{~N}_{2} \mathrm{OCl}[\mathrm{M}+\mathrm{H}]^{+} 299.0946$ found 299.0951

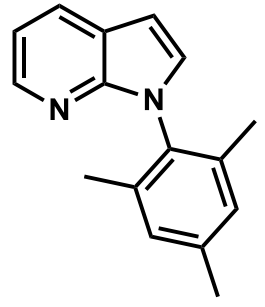




\section{1-Mesityl-1H-pyrrolo[2,3-b]pyridine}

The general procedure was followed $\left(50{ }^{\circ} \mathrm{C}, 24 \mathrm{~h}\right)$. GC-MS conversion: $70 \%$ after $24 \mathrm{~h}$. Unseparable mixture of mesityl and phenyl substituted products (product ratio: 11.5:1).<smiles>Cc1cc(C)c(-n2ccc3cc(Br)cnc32)c(C)c1</smiles>

\section{5-Bromo-1-mesityl-1H-pyrrolo[2,3-b]pyridine}

The general procedure was followed $\left(50{ }^{\circ} \mathrm{C}, 24 \mathrm{~h}\right)$. GC-MS conversion: $62 \%$ after $24 \mathrm{~h}$. Unseparable mixture of mesityl and phenyl substituted products (product ratio: 11.5:1).

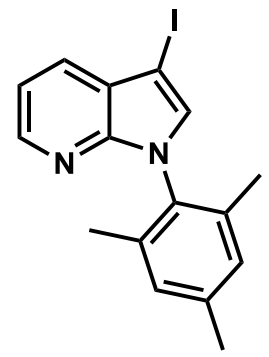

\section{3-Iodo-1-mesityl-1H-pyrrolo[2,3-b]pyridine}

The general procedure was followed. GC-MS conversion: 100\% product ratio: 19:1. Yellow solid (80 mg, 0.67 mmol, yield: 67\%). $\mathrm{R}_{\mathrm{f} .:} 0.36$ (in hexane:EtOAc 9:1), M.p.: 119-121 ${ }^{\circ} \mathrm{C},{ }^{1} \mathrm{H}$ NMR $\left(250 \mathrm{MHz}, \mathrm{CDCl}_{3}\right) \delta 8.33(\mathrm{~d}, J=4.7 \mathrm{~Hz}, 1 \mathrm{H}), 7.82(\mathrm{~d}, J=7.8 \mathrm{~Hz}, 1 \mathrm{H}), 7.29(\mathrm{~s}, 1 \mathrm{H}), 7.18$ (dd, $J=7.9,4.7 \mathrm{~Hz}, 1 \mathrm{H}), 7.03(\mathrm{~s}, 2 \mathrm{H}), 2.36(\mathrm{~s}, 3 \mathrm{H}), 1.92(\mathrm{~s}, 6 \mathrm{H}) \mathrm{ppm} .{ }^{13} \mathrm{C}$ NMR $(63 \mathrm{MHz}$, $\left.\mathrm{CDCl}_{3}\right) \delta 147.7,145.3,139.4,136.9,133.2,133.0,129.9,129.6,123.2,117.3,55.2,21.6,18.1$ ppm. MS (EI, $70 \mathrm{eV}): m / z(\%): 362\left(88,\left[\mathrm{M}^{+}\right]\right), 235$ (96), 220 (100), 205 (43), 119 (29), $110(56)$, 91 (31) 77 (27). IR (ATR), 1609, 1590, 1564, 1497, 1479, 1455, 1433, 1406, 1373, 1313, 1301, $1272,1215,1197,1155,1108,1029,1014,980,962,949,915,884,853,806,790,764,702,622$, $607 \mathrm{~cm}^{-1}$. HRMS calcd for $\mathrm{C}_{16} \mathrm{H}_{15} \mathrm{~N}_{2} \mathrm{I}[\mathrm{M}+\mathrm{H}]^{+} 363.0353$ found 363.0357 


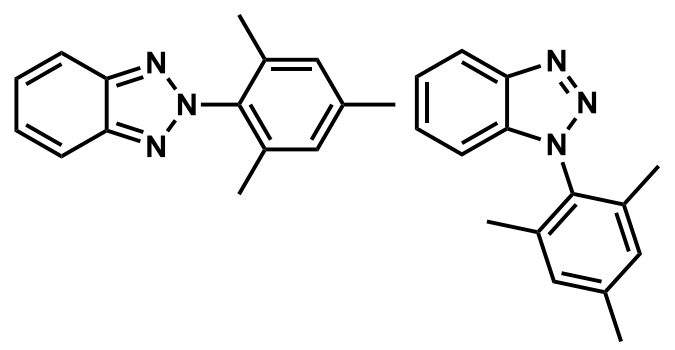

2-Mesityl-1H-benzo[d][1,2,3]triazole and 1-mesityl-2H-benzo[d][1,2,3]triazole

The general procedure was followed. GC-MS conversion: $100 \%$ product ratio: $2 \mathrm{~N} / 1 \mathrm{~N}$ 2:1.

\section{Computational Details}

The calculations have been performed using the $\omega$ B97X-D range-separated hybrid exchangecorrelation functional by using the Gaussian 09 package. ${ }^{30}$ The $\omega$ B97X-D functional has been shown to perform remarkably well for noncovalent interactions and thermochemistry. ${ }^{31}$ Ultrafine grid has been employed for all calculations. The 3D structures presented in the article have been visualized by using the Cylview software. ${ }^{32}$ For geometry optimizations and frequency calculations we have employed the $6-31+\mathrm{G}^{*}$ basis set (atoms $\mathrm{H}, \mathrm{C}, \mathrm{N}, \mathrm{O}, \mathrm{F}, \mathrm{S}, \mathrm{Cl}$ and $\mathrm{Br}$ ), whereas for iodine we selected the LanL2DZ basis set completed with a set of polarization and diffuse functions taken from the corresponding aug-cc-pVDZ-PP basis set. $^{24}$ Single point dichloro-ethane solvated electronic energies have been calculated for the optimized structures using a larger basis set: LanL2TZ(f) with additional set of polarization and diffuse functions from the aug-ccpVTZ-PP for iodine and the $6-311++\mathrm{G}(3 \mathrm{df}, 3 \mathrm{pd})$ set for all the other atoms. Solvent corrected free energies have been calculated within the harmonic oscillator, rigid rotor, ideal gas approximation. For further computational details and for a discussion of possible error sources see SI.

\section{ASSOCIATED CONTENT}




\section{Supporting Information}

The Supporting Information is available: experimental details and selectivites, calculation details, stability data, error analysis, activation barriers, XYZ data of the structures; free of charge on the ACS Publications website at DOI: .

\section{AUTHOR INFORMATION}

\section{Corresponding Author}

E-mail: stirling.andras@ttk.mta.hu

E-mail:novakz@elte.hu

\section{Notes}

The authors declare no competing financial interest.

\section{ACKNOWLEDGMENT}

We acknowledge the computational resources of NIIF, OTKA Grants K101115, K116034, the Hungarian Academy of Sciences (LP2012-48/2012) and Ádám Madarász for fruitful discussions.

\section{REFERENCES}

1) General reviews on the synthesis and application of hypervalent iodonium salts: a) Zhdankin V. V.; Stang P. J. Chem. Rev. 2008, 108, 5299-5358.; b) Zhdankin V. V. Hypervalent Iodine Chemistry, Wiley, Chichester, 2014, pp. 1480; c) Yusubov M. S.; Maskaev A. V.; Zhdankin V. V. ARKIVOC 2011, 370-409.; d) Silva, Jr. L. F.; Olofsson B. Nat. Prod. Rep. 2011, 28, 1722-1754.; e) Charpentier J.; Früh N.; Togni A. Chem. Rev. 2015, 115, 650-682.; f) Yoshimura A.; Zhdankin V. Z. Chem. Rev. 2016, 116, 3328-3435.

2) Reviews on the synthesis and application of diaryl iodonium salts: a) Merritt E. A.; Olofsson B. Angew. Chem. Int. Ed. 2009, 48, 9052-9070.; Grushin V. V. Chem. Soc. Rev. 2000, 29, 315-324.; c) Oloffson, B. Top. Curr. Chem., 2015, 1-32. d) Aradi, K.; Tóth, B. L.; Tolnai, G. L.; Novák, Z. Synlett, 2016, DOI: 10.1055/s-0035-1561369

3) a) Kang, Yoon S. K.; Kim Y.-M. Org. Lett., 2001, 3, 2697-2699. b) Vaddula B.; Leazer J.; Varma R. S. Adv. Synth. Catal. 2012, 354, 986-990. c) Niu H.-Y., Xia C.; Qu G.-R.; Zhang Q.; Jiang Y., Mao R.-Z.; Li D.-Y.; Guo H.-M. Org. Biomol. Chem. 2011, 9, 5039-5042. d) Zhou T.; Li T.; Chen Z.-C. Helv. Chim. Acta 2005, 88, 290-296. e) Zhou T.; Chen Z.-C. Synth. Commun. 2002, 32, 903-907. f) Rewcastle G. W.; Denny W. A. Synthesis 1985, 220-222. g) Scherrer R. A.; Beatty H. R. J. Org. Chem. 1980, 45, 2127-2131. h) Wang L.; Chen Z.-C. J. Chem. Res. Synop. 2000, 2000, 367-369. i) Ackermann L.; Vicente R.; Kapdi A. R. Angew. Chem., Int. Ed. 2009, 48, 9792-9826. 
4) Guo F.; Wang L.; Wang P.; Yu J. Han J., Asian J. Org. Chem. 2012, 1, 218-221.

5) Carroll M. A.; Wood R. A. Tetrahedron 2007, 63, 11349-11354.

6) Beringer M. F.; Brierley A.; Drexler M.; Grindler E. M.; Lumpkin C. C. J. Am. Chem. Soc. 1953, 75, 2708-2712.

7) Ghosh R.; Lindstedt E.; Jalalian N. Olofsson B. Chem. Open, 2014, 3, 54-57.

8) a) Wen J.; Zhang R.-Y.; Chen S.-Y.; Zhang J.; Yu X.-Q. J. Org. Chem. 2012, 77, 766-771.; b) Kita, Y.; Dohi, T. Chem. Record 2015, 15, 886-906.

9) Gonda Zs.; Novák Z. Chem. Eur. J. 2015, 21, 16801-16806.

10) Norrby P.-O.; Petersen T. B.; Bielawski M.; Olofsson B. Chem. Eur. J. 2010, 16, 8251-8254.

11) Malmgren J.; Santoro S.; Jalalian N.; Himo F.; Olofsson B. Chem. Eur. J. 2013, 19, 10334-10342.

12) Oh C. H.; Kim J. S.; Jung H. H. J. Org. Chem. 1999, 64, 1338-1340.

13) Ochiai M.; Kitagawa Y.; Toyonari M. ARKIVOC 2003, 43-48.

14) Tinnis F.; Stridfeldt E.; Lundberg H.; Adolfsson H.; Olofsson B. Org. Lett. 2015, 17, 2688-2691.

15) Shi W.-M.; Ma X.-P.; Pan C.-X.; Su G.-F.; Mo D.-L. J. Org. Chem. 2015, 80, 11175-11183.

16) Mehra M. K.; Tantak M. P.; Kumar I.; Kumar D. Synlett 2015, 27, 604-610.

17) Carroll M. A.; Martin-Santamaria S.; Pike V. W.; Rzepa H. S.; Widdowson D. A. J. Chem. Soc. Perkin Trans. 1999, 2, 2707-2714.

18) Martin-Santamaria S.; Carroll M. A.; Carroll C. M.; Carter C. D.; Rzepa H. S.; Widdowson D. A.; Pike V. W. Chem. Commun. 2000, 649-650.

19) Pinto de Magalhaes H.; Lüthi H. P.; Togni A. Org. Lett. 2012, 14, 3830-3833.

20) Pinto de Magalhaes H.; Lüthi H. P.; Togni A. J. Org. Chem. 2014, 79, 8374-8382.

21) Iwama T.; Birman V. B.; Kozmin S. A.; Rawal V. H. Org. Lett. 1999, 1, 673-676.

22) Yamada, Y.; Okawara, M. Bull. Chem. Soc. Jpn. 1972, 45, 2515-2519.

23) Tolnai G. L.; Székely A.; Makó Z.; Gáti T.; Daru J.; Bihari T.; Stirling A.; Novák Z. Chem. Commun. 2015, 51, 4488-4491.

24) For further details see the SI.

25) For a discussion of the calculation of the deprotonation barrier see SI.

26) The experimental yields ${ }^{9}$ and the calculated barriers are listed in the SI.

27) The experimentally measured yields are converted to activation energies by assuming the validity of transition state theory and using the equation: $\Delta \Delta G^{\#}=\Delta G_{2}^{\#}-\Delta G_{1}^{\#}=R T \ln \frac{c_{1}}{c_{2}}$, where $\mathrm{c}_{1}$ and $\mathrm{c}_{2}$ are the experimental GC-MS yields.

28) Marenich A. V.; Cramer C. J.; Truhlar D. G. J. Chem. Theor. Comp. 2013, 9, 609-620.

29) Arylation of the $3 \mathrm{C}$ site would require even a higher, $35 \mathrm{kcal} / \mathrm{mol}$ activation free energy.

30) Gaussian 09, Revision D.01, Frisch, M. J. et al. Gaussian, Inc. 2013. 
31) a) Chai, J.-D.; Head-Gordon, M. Phys. Chem. Chem. Phys. 2008, 10, 6615-6620.; b) Grimme, S. Wiley Interdisc. Rev. Comput. Mol. Sci. 2011, 1, 211-228.

32) CYLview, 1.0b; Legault, C. Y., University of Sherbrooke, 2009 (http://www.cylview.org) 